\title{
¿Cómo pensar la calificación laboral en el marco de una cultura de la cooperación?
}

Geyser Margel*

\section{Resumen}

El objetivo de este artículo es presentar una reflexión sobre el concepto de Calificación Laboral en el contexto de construcción de una cultura de la cooperación entre empresarios y trabajadores, en el marco de nuevas relaciones y nuevos compromisos en una empresa papelera uruguaya. No obstante, intenta ser una invitación para pensar otras experiencias. Se concluye: a) Que la nueva cultura implica ruptura y reconstrucción de nuevos lazos sociales dentro de la empresa; b) Que el proceso de construcción de una nueva cultura de la confianza pone en jaque tradicionales identidades de empresarios y trabajadores; y c) Se propone indagar los valores, creencias e imágenes de empresarios y trabajadores como componentes sustantivos de la calificación laboral, al discutir estrategias y polfticas de relaciones laborales, por un lado y comprender las fuerzas restrictivas o impulsoras que fijan los límites y alcances de una cultura de cooperación, por el otro.

Palabras claves: Calificación laboral, cultura, cooperación, empresarios, trabajadores, identidad, Uruguay.

Recibido: 05-10-95 . Aceptado: 25-02-96

- Socióloga. Estudiante del Doctorado en Ciencia Social con especialidad en Sociología. Colegio de México. 


\section{¿How to think the labor qualification within a cooperative culture?}

\section{Abstract}

The objective of the article is to reflect about the concept of labor qualification in the context of building a cooperative culture between workers and employers. Such a reflection is based on the process of building new relationships, new agreements, new roles in an Uruguayan paper producing enterprise. Nevertheless, this reflection tries to be an invitation to think about other experiences. The article concludes: a) The new culture implies either breaking up or rebuilding new social links within the enterprise, b) The process of building a new culture of trust questions the traditional identities of employers and employees, and c) It proposes looking into values, beliefs and images in employers and employees as substantive components of labor qualification when discussing strategies and labor relationships policies, on the one hand, and understanding the restrictive or impelling forces which determine boundaries and potentialities of a culture of trust, on the other.

Key words: qualification, labor, culture, cooperation, employers, employees, identity, Uruguay.

\section{Introducción}

Cuando nos enfrentamos hoy a discursos empresariales que se enarbolan y pintan con una apelación a la participación de los trabajadores en las decisiones de gestión del trabajo, a la implicación, a la incorporación del conocimiento operario, etc.; observamos de forma clara, un modelo de trabajador en el cual está pensando la empresa y con el que proyecta explicita o implicitamente las transformaciones productivas que quiere llevar a cabo. La empresa construye una "imagen" de trabajador, un modelo que encierra y contiene las habilidades, las aptitudes y los comportamientos necesarios para desarrollar un trabajo específico. La empresa define "el contenido de calificación" requerida, asi como trasmite en su discurso la necesidad de construcción de una nueva cultura de trabajo; oímos de la boca de los empresarios expresiones como: "construcción de nuevas relaciones entre actores", "relaciones adultas y maduras".

Este trabajo es una reflexión más en el andado camino de tantos cientistas sociales que discuten los nuevos alcances de la calificación laboral en instancias productivas en las cuales la apelación al "obrero gestor" pone en el tapete, novedosos perfiles y contenidos del concepto, nuevos roles de los actores, así como la tan compleja y difícil construcción de una cultura de cooperación. Me ubico en el contexto de una empresa papelera uruguaya que pretende, y que ya ha comenzado a realizar, una serie de transformaciones productivas y de organización del 
trabajo. A saber: diversificación de sus productos en un contexto de flexibilidad productiva que apunta a buscar nichos de mercados externos; automatización de los procesos, organización de equipos de trabajo autónomos y autodirigidos apelando a la polifuncionalidad y multihabilidad de los operarios. Estas implementaciones se han desarrollado en un marco en el cual la empresa ha acudido a programas de Calidad Total y de rediseño.

Las relaciones laborales que empresarios y trabajadores están desarrollando, nos muestran también un giro novedoso en el contexto unuguayo de las prácticas y trayectorias tradicionales de confrontación, hacia formas de negociación y concertación. La participación del sindicato como actor reconocido por la empresa en las discusiones sobre reestructura, productividad y calificación es un ejemplo de lo referido. No está demás aclarar, que es la primera empresa uruguaya que hoy por hoy está discutiendo conjuntamente con el sindicato un convenio laboral de carácter no taylorista.

Se expone aquí, cuál ha sido el camino -no agotado aún, sino en construcción- que han tomado ambos actores en el escenario de algo tan "complejo" y "traumático" como es la modificación de los comportamientos en aras de la construcción de una cultura de la cooperación; propuesta que se funda en la capacidad de generar relaciones de credibilidad entre los actores.

Desde esta última perspectiva, las exigencias de calificación pasan también a centrarse en actitudes y comportamiento, tipo de relaciones entre pares, pero también entre empresarios y trabajado- res, elementos que son evidenciados por la empresa como comprensivos de la calificación, los que suponen una necesaria transformación de las formas tradicionales de relacionamiento. La noción de ca* lificación y de cultura de trabajo están estrechamente interrelacionadas, estudios como el de Paul Thompson sobre los obreros de Coventry, nos han señalado cómo es necesario aprehender el contenido de la primera en contextos sociotemporales y culturales especificos. La calificación es socialmente construida en la práctica cotidiana del espacio del taller, pero también lo es desde la educación de un pais, desde las políticas de relaciones laborales, la estructuración del mercado de trabajo, etc.

Dos son los objetivos propuestos: en primer lugar, señala los If́mites y los alcances que se vislumbran para la construcción de una cultura de la cooperación entre empresarios y trabajadores en el contexto especffico de las trayectorias de ambos actores de la empresa referida; $y$, en segundo término proponer un enfoque de investigación que allane el camino para comprender tales alcances y limitaciones.

\section{La competencia como elemento central del concepto de callficación y del modelo de trabajador}

Es la noción de calificación como competencia la que tanto gira y gira en el ámbito empresarial, "competencias para hacer esto o lo otro porque se apunta a la competitividad". Una revisión teórica sobre el concepto de calificación es una 
tarea titánica, existen tantas definiciones como autores se han preocupado por él y tantas perspectivas de abordajes empiricos como investigaciones han sido realizadas. Lo que sf es central es la consideración heurística del concepto, así como su carácter de socialmente construido. EI concepto de calificación tiene un tiempo y espacio especifico de significación (Thompson, 1989), es un concepto relativo y complejo' que puede asumir tantos contenidos como actores se refieran $a$ é $^{2}$.

La noción de calificación como competencia nos remite a las transiormaciones de los saberes necesarios para la acción en las nuevas formas de organización del trabajo (Dugué, 1994), -saberes ser y saberes hacer- un conjunto pues de conocimientos, de tipos de conducta, y formas de razonamiento que permiten saber con quién se puede contar para el cumplimiento de tareas y trabajos especlficos (Lichtenberger, 1994).

"Saber con quién se puede contar", ¿difficil tarea, verdad?. Porque diagnosticar el nivel y el tipo de conocimientos requeridos léase conocimientos sobre matemáticas, física, química o informáti$\mathrm{ca}$, etc.- parece una tarea no tan compleja, y si hay además voluntad empresarial de emprender políticas de capacitación a los trabajadores o de exigir tales niveles de formación al momento de contratar personal, aparentemente el problema se resolverla.

Pero no es un problema solo de voluntades, sino que desde la perspectiva empresarial implica un cambio sustancial de sus referencias sobre las relaciones de trabajo y sobre la integración de la inteligencia operaria a los procesos de trabajo, cambio que pone en jaque una cultura empresarial que ha mantenido "al costado" la participación de los trabajadores en los espacios de la producción. Las exigencias de habilidades y conocimien. tos que requiere la introducción de tecnología de punta, así como la reorganización del trabajo en grupos es una dimensión de la calificación requerida, pero también está presente una dimensión personal y social de los individuos como componentes de la misma. Son pues estas últimas dimensiones las que comple-

1 Y siempre volvemos al origen... ¿Cómo no tener presente a Naville en las revislones que hoy se hacen sobre el concepto referido? En Essal sur la quallication du travall, 1956, señalaba la necesided de abordar las calficaciones en su esencla relativa y conflictiva, considerando que era menester referirse a ellas como la expresión de las luchas y los procesos de quienes están involucrados en su codificación, clasiflcación y evaluaclón a traves de los salarios y el prestiglo que otorgan la posesión de las mismas.

2 Según Lichtenberger (1982), "Para el trabajador son las capacidades que posee, el conjunto de lo que 6 l se siente capaz de hacer y puede utilizar en el trabajo para obtener un salarto; para el ingeniero, lo que interesa sera saber sl tal individuo tiene las aptitudes necesarias para la organización prevista del trabajo.

La calíicación se verificará entonces mediante pruebas, test o entrevistas en función de un puesto de trabajo dado; para el patrón de la empresa, menos interesado en el aspecto concreto del trabajo, lo que importa es saber lo que debera pagar en funclón de lo que utiliza, y por lo tanto, la clasificación; para el aprendiz o alumno, la calfícación es el oficlo que espera adquirir, es decir, lo que defíne para qué es bueno y dónde se lo necesita, lo que le dará su ublcación en la sociedad. Para sus capacitadores seré la referencla establecida por la lista de saberes que tienen que trasmitirie y sobre los cuales serta evaluado para obtener su diploma; el sindicallsta, interesado también por todas las dimensiones de la calficaclón, se Ilmitará a veces sólo a los aspectos de la calificación reconocidos en las convenciones". 
jizan más el problema de la calificación, ya que las exigencias "del nuevo saber ser" colocan en una situación de tensión antiguos comportamientos que refieren al lugar asignado al trabajador por el taylorismo. Desde esta perspectiva la calificación comportamental es central en los discursos empresariales, asociándola a la calidad de la producción y a la mejora de la productividad.

\section{Algunos elementos de la cultura laboral uruguaya}

Para acercarnos y comprender una nueva cultura laboral es necesario conocer cuál es la vieja. Los empresarios a los que me remito hablan de la necesidad de cambio, de participación y de integración de la inteligencia obrera al proceso de trabajo, de la construcción de relaciones sobre la base de la confianza, de respeto y beneficio mutuo entre ellos y los trabajadores. Los trabajadores se preguntan ¿por qué ahora?, porque en la práctica ellos han sido propositivos de mejoras de los procesos, y ven por lo tanto en las nuevas apelaciones la institucionalización de una práctica de uso corriente. Tal institucionalización es una de las dimensiones puestas en jaque, pero no es sólo la única ni la fundamental. Es el "lugar" que los trabajadores han tenido en la gestión del trabajo, as / como sus concepciones ideológicas sobre lo que "debla" hacer, lo que también está en juego.

Por tales consideraciones conocer "los lugares" y "las concepciones" de los roles de los actores es esencial para acercarnos a la comprensión de los límites de las nuevas propuestas.
Históricamente, el rasgo fundamental de los empresarios uiruguayos ha estado en los Iimites de una racionalidad de inversión. Un rastreo histórico nos muestra la conformación de un empresariado focalizado en actividades agro-productivas que crece y se nutre de las polfticas proteccionistas del Estado. Las poIíticas estatales han sido habilitantes de una especialización de las empresas en determinadas lineas de productos, definiendo los límites de la competencia en el mercado interno -en muchos casos con la consecuente conformación de monopolios-, así como los espacios de integración a mercados ampliados. La industria uruguaya surge produciendo bienes de baja calidad. El perfil de gestión tecnológica, también elemento central de la cultura empresarial, ha estado guiado por la debilidad y el carácter puntual de su introducción, asl como por una práctica -no generalizable- de montaje y adaptación con recursos humanos locales.

En sintesis, un empresariado con una racionalidad más rentista que productiva, que despega en un contexto económico de alta protección. Un empresariado portador de una cultura social y de una experiencia histórica que los hace proclives al desarrollo de una politica de relaciones laborales asimilada como el lugar de "choque" con las demandas sindicales y la indisciplina individual de los obreros (Rama y Silveira, 1991). En este marco, el aspecto central de dicha conflictividad se focalizó en la politica de remuneraciones, ya que desde ella -y más allá de la protección arancelaria- se pesaban los costos industriales y los precios.

Los trabajadores uruguayos se or- 
ganizan en forma temprana on una estructura sindical autónoma del Estado y la empresa. Las políticas de gobiemo y las estrategias empresariales han colocado sistemáticamente al actor sindical en situaciones de conflictividad y confrontación por el salario (De Oliveira y Massera, 1993). Aunado a esto, la exclusión de los trabajadores en las definiciones de las formas y los contenidos del trabajo ha sido formalmente regulada en las prácticas contractuales de los convenios laborales.

Este ha sido el marco de referencia de la relación entre empresarios y trabajadores de la empresa que es toco de atención de este trabajo.

\section{El rumbo de las relaclones laborales y las prácticas llevadas a cabo por la empresa y el sindlcato}

Habiendo reseñado brevemente las concepciones socialmente construidas sobre los alcances y límites de la relación entre trabajadores y empresarios, podemos plantear sintéticamente el rumbo que están tomando hoy las relaciones laborales aludidas.

En 1990 la empresa comienza a hacer planteos sobre la necesidad de rea. lizar un proceso de flexibilización laboral que apunta fundamentalmente a modificar las condiciones de régimen de trabajo proponiendo un sistema de licencias rotativas, la eliminación de algunas funciones y la redistribución de personal. Estas propuestas son rechazadas por la organización sindical. La empresa decide el lock out, iniciándose un conflicto que culmina con el despido de 117 trabajadores. En 1991 la empresa plantea la creación de círculos de calidad, propuesta que también es rechazada por el sindicato. 1992 es un año clave, ya que hay un recambio en la composición del directorio y de las gerencias de la empresa. La necesidad de reestructuración productiva de la empresa es un desafio de sobrevivencia económica en el contexto del Mercosur. La empresa necesita revertir la "imagen" que de ella tenía la opinión pública y los trabajadores. Se crea la gerencia de $R e-$ cursos Humanos y a comienzos de 1993 acude a una serie de consultorías que realizan estudios sobre la viabilidad del mercado y sobre clima socio-organizacional. Una consultora especialista en calidad total recomienda a la empresa la realización de un estudio de rediseño productivo y la participación sindical en dicho proceso.

La organización sindical decide participar, pero plantea las siguientes condiciones: que no hubiera despidos compulsivos, que se capacitara y se calificara a los trabajadores y que se reconociera al sindicato como el actor de la negociación del sistema de remuneraciones, la selección del personal para el trabajo en equipos y la reorganización del trabajo; la empresa acepta las condiciones presentadas por el sindicato.

El primer paso dado hacia la construcción de una cultura de la cooperación es la instrumentación de cursos de capacitación sobre calidad total -estructurados en cascada desde los directivos y que culmina en los operarios-en los cuales se trasmite la necesidad de construir una "nueva mentalidad laboral" y se estimulan 
las virtudes del trabajo en equipo. El programa de calidad total se acompaña del estudio de un rediseño de puestos y funciones. El rediseño organizacional fue un estudio técnico del proceso de producción y del funcionamiento de la fábrica para detectar las actividades que no le daban valor al producto, apuntando como idea básica a la implementación de la producción en equipos de trabajo autodirigidos, semi-autónomos, polifuncionales y multihábiles. La conformación de equipos elimina la supervisión que la olicina de control y métodos tiene sobre la producción. Los equipos tendrían como tareas el control estadístico de los procesos, el control de calidad de productos, asi como el mantenimiento de la maquinaria.

La excelencia de la producción es vista como el producto de la integración entre trabajadores y empresa en la búsqueda de un proposito común, de la generación de un clima propicio y del estrechamiento de lazos. Naturalmente la apelación a una nueva definición de la comunicación entre cargos directivos y operarios está presente. El "conocimiento" y el "involucramiento" pasan a ser para esta empresa factores sustanciales de la diferenciación en el mercado y de oportunidades de competencia. La implicación laboral, apelación recurrente, es presentada como una necesidad para la optimización de los procesos productivos y como rasgo básico de la calificación. En este sentido no debe olvidarse la consideración de la implicación como el resultado de políticas de gestión de la fuerza de trabajo y las formas $\theta$ instrumentos que se utilizan para llevarlas a cabo (Castillo, 1991).

El curso de esta experiencia nos muestra una ruptura muy importante desde la perspectiva histórica de las relaciones laborales en el Uruguay. En primer término, vemos un empresariado que acuciado por la coyuntura económica redefine su estrategia en un marco en el cual ya el Estado no tiene el peso proteccionista sobre el cual creció y despegó la industria papelera, realizando hoy grandes inversiones en tecnología y tratando de establecer una nueva relación con los trabajadores que se aleja del viejo perfil de la confrontación. La premisa sobre la cual se levanta el actual discurso de la empresa nos ubica en la propuesta de la teorla del capital humano (Shultz, 1971) que concibe el recurso humano como el capital más importante de la empresa.

Pero también para los trabajadores la situación es novedosa $\theta$ impactante, porque si bien es cierto que la experiencia del rediseño cuestiona las estructuras tayloristas de la empresa, asi como los símbolos de la cultura empresarial, también cuestiona las prácticas de los trabajadores y la producción simbólica de las mismas. La encrucijada productiva cuestiona en términos ideológicos las bases del sindicalismo uruguayo, poniendo al actor sindical en una situación de redefinición o no de sus perfiles tradicionales.

No fue una situación de paralización la adoptada por los trabajadores de nuestra empresa; en 1993 a solicitud de ellos se firma un convenio tripartito entre el sindicato, la empresa y el Departamento de Sociología de la Universidad de la 
República para realizar un estudio sobre el trabajo y el perfil de formación de la fuerza de trabajo de la fábrica, investigación que es financiada en un $70 \%$ por la empresa y el $30 \%$ por el sindicato. Es el conocimiento formalizado sobre el trabajo y los perfiles de calificación uno de los objetivos centrales que llevan al sindicato a tal propuesta.

La práctica de asesoramiento sobre el tema de relaciones laborales continúa hoy por hoy. Actualmente el sindicato y un investigador del Departamento de Sociologla están discutiendo las bases para la firma del primer convenio no taylorista en el pais.

El perfil de la concertación parece ser el rumbo que han decidido los trabajadores de esta empresa, un cambio cultural sustancial que es percibido por ellos y ante el cual temas como el de la calificación, la productividad y los límites de la injerencia en la gestión del trabajo están en el orden del dla de sus discusiones. Es un proceso autocritico sobre viejas estrategias que están siendo puestas en jaque por nuevas decisiones empresariales. Ejemplo de tales reflexiones es lo expresado por sindicalistas sobre el conflicto de 1990: "Nos faltó una visión global de la industria del papel y de lo que pasaba en el mundo. Los empresarios nos decían que estaba en crisis, pero nosotros, como venía de ellos, nunca se lo admitimos, ni lo analizamos, ni pudimos sacar las conclusiones necesarias. Fue un análisis a la vieja usanza, a la histórica. Vamos a pegarporque ahiestá el enemigo, y nos faltó una adaptabilidad a situaciones que estaban alli, que eran nigurosamente ciertas, mal que nos pese". Refiriéndose a las prácticas de negociación sostiene: "Hoy por hoy, toda esta dinámica de discusión, de negociación, ha llevado a que reflexionemos, ya no como dingentes sindicales, sino toda la gente, de qué tipo de cosas son las que aconsejan los tiempos, por eso hablamos de determinado tipo de táctica, que no quiere decir que perdamos 10 que han sido los valores históricos como movimiento sindical, ni determinado tipo de movilización llegado el caso. Creemos que no, pero si deberán vincularse a determinadas consideraciones que tiene que tener nuestro análisis".

Pero no sólo es una estrategia sindical referida a la empresa la que está siendo cuestionada sino que es la relación del trabajador con su trabajo y el significado de éste último lo que está cambiando. Aunado a los nuevos requisitos de un trabajo abstracto, inteligente y de manejo de diferentes lógicas, se agrega como componente de la calificación un nuevo comportamiento en las relaciones de trabajo que rompe con la lógica de las estructuras jerárquicas predominantes y con los contenidos de lo comunicable. Las capacidades personales de inventi$v a$, ingenio y de relacionamiento social son tan valoradas como los niveles de educación, la experiencia, etc.

\section{Reflexiones finales}

La noción de nuevo reparto de barajas y de quiebre del silencio productivo (Thuderoz, 1995) es muy sugerente para contextualizar las relaciones laborales emergentes. Se propone una nueva forma de actuar en común ligada a nuevas formas de organizar el trabajo en la em- 
presa, modalidades que apelan a la cooperación entre obreros, mandos medios, superiores y técnicos, etc. Cooperación que requiere de la redefinición de códigos y del contenido de las comunicaciones que se entablan, innovaciones que rompen con el secreto sobre la producción que era detentado por la empresa. Esta ruptura implica, parafraseando al autor referido, una reconstrucción de los lazos sociales al interior de la empresa en la medida que se genera un espacio y una situación de construcción de nuevas identidades laborales.

Dos requisitos que se presentan como esenciales en la construcción de la nueva cultura de trabajo basada en la optimización de las relaciones comunicacionales como contenidos de la caliticación son: la construcción de un acuerdo intersubjetivo sobre la validez de los objetivos de producción expresables en el lenguaje y la consideración de las calidades individuales, entendiéndose por ello "las facultades de auto-aprehensión y de auto-control de sus campos de acción, que integran conocimientos, comprehensiones, pero también dominio de las circunstancias de la acción social y de la acción individual". (Philippe, 1993:23)

Para el cumplimiento de estos requisitos es necesaria una transtormación muy importante de las visiones autoperceptivas y autorreferentes de los actores empresariales y obreros, transformación que pone en jaque una identidad "tradicional" de los actores y que reflere en palabras de Dubet, a un nuevo "trabajo del actor", un nuevo trabajo en una realidad que sigue su proceso de construcción y que ahora se reconstruye sobre nuevas experiencias sociales y personales vislumbradas tanto en el ámbito de la fábrica como en el de la sociedad en la que están insertos los actores. Desde esta perspectiva es importante el rumbo que los empresarios y los trabajadores de la empresa están construyendo. Si el trabajo hoy no sólo exige habilidad, conocimientos formalizados, buenas redes de comunicación de los saberes, sino implicación y cooperación, el escenario del espacio de la fábrica nos presenta a tra. bajadores y empresarios ante la necesaria producción de nuevos contenidos a regular. No sólo es necesario concertar el salario, el perfil de las tareas, o la calidad de los productos, sino que la apelación a la cooperación entre ambos actores nos sitúa ante la consideración de calidades personales y sociales también como ele- mentos de concertación.

Estos elementos se vislumbran en las relaciones laborales a las que hemos estado haciendo alusión, pudiendo proponer como hipótesis que existen potencialidades para la estructuración de una nueva cultura laboral. Pero naturalmente el proceso de construcción de una cultura de la confianza y de credibilidad entre actores que han estado enirentados implica la reconstrucción de nuevos acuerdos intersubjetivos sobre el significado y los roles de los actores en el lugar de la producción, acuerdos que obligan al respeto y al mantenimiento de las garantias y condiciones que ambos propongan como centrales de las negociaciones, ya que la fuerza de la credibilidad estará constantemente "vigilada" desde las prácticas que empresarios y trabajadores lleven a cabo. La implementación de los 
acuerdos referidos suponen un "doble trabajo", ya que es un proceso cultural que implica la elaboración desde los actores de un nuevo "ser" empresario y nuevo "ser" obrero, siendo en esa construcción que ambos realicen la fundación de una nueva cultura laboral.

Las transformaciones de los procesos de producción y de las calificaciones de los trabajadores han sido y son elementos centrales de discusión en el plano académico, así como desde la perspectiva de las políticas educativas y de las relaciones laborales. Preguntas como: ¿cuáles deben ser los cambios necesarios de los currícula escolares?, ¿cuáles deben ser las estrategias de negociación?, el cómo de las estructuras del mercado de empleo y de trabajo, las políticas tecnológicas, etc.; están presentes en tales preocupaciones. Todas estas discusiones son de suma importancia, pero, podrian tener otro alcance si consideraran las concepciones que trabajadores y empresarios tienen en referencia al trabajo y hacia las relaciones que se construyen en el ámbito de su efectivización. Las regulaciones de las relaciones laborales encarnan una dimensión de la cul- tura laboral, ellas son en si mismas constitutivas de tal cultura, por lo que el discermimiento de los fundamentos y las bases culturales de tales regulaciones se presenta como un desafio que debe ser abordado.

Si hay un espacio de la productividad $^{3}$ que está condicionada por la calidad de las individualidades on la actividad comunicacional que se establece en el ámbito de trabajo, es necesario conocer esas individualidades y sus referentes de identificación hacia el trabajo, en breve, conocer las formas de identidad laboral. Es precisamente esta propuesta la que se plantea y sugiere como relevante desde una perspectiva de investigación como medio que habilite a profundizar en los componentes que subyacen en las prácticas $y$ en las lógicas empresariales $y$ obreras. Indagar en los valores, en las creencias, en las imágenes construidas, podría aportar elementos sustanciales al momento de definir estrategias y políticas de relaciones laborales, asi como lluminar el camino para la comprensión de las fuerzas restrictivas o impulsoras que fijan los límites y los alcances de una cultura de la cooperación.

3 En este sentido me remito a los sigulentes trabajos de Philippe Zarfian, Los nuevos enfoques de la productividad (1993), "De la productivité des ressources a la productivitá d'organisation" (1994) y "L'organisation qualiffante: de la qualité de l'aprendissage professionel à l'efficience economique " 1994). Al plantear la relación entre productividad y estructuración de sistemas de comunicación, Zarifian sostiene que la productividad es la velocidad de reallzaclón de un volumen determinado de transacciones comunicacionales. Si la productlvidad son transacciones, es necesario entonces indagar en los elementos que constituyen la vabilidad o no de las mismas. En este sentido señala que el rol del saber profeslonal, el rol del saber social, asi como la actividad comunicacional son esenciales para la dlscusión de la productividad. 


\section{Referenclas Blbliográficas}

Castillo, Juan José (compilador) (1991). La automación y el futuro del trabajo. Diseno de trabajo y cuallflcación de los trabajadores, Ministerio de Trabajo y Seguridad Social, Madrid.

Castillo, Juan José y Santos, Maximiano (1994). "La cualificación del trabajo y los distritos industriales", Economia y Soclologia del Trabajo, No. 20, Es* paña.

De Oliveira, Lucla y Massera Ema (1993). "Estrateglas de organlzaclón empreserial y nuevas formas de competitivldad que se esbozan", Documento de trabajo No. 34, Departamento de Sociologia, Universidad de la República, Montevideo.

Dugué, Elizabeth (1994). "La gestion de las competenclas: los saberes devaluados, el poder oculto", Soclologie du Travall, XXXIV, Parls.

Uchtenberger, Ives (1992). "La calificación: apuesta social, desafío productivo", Formación Profesional: Callflcaclones y claslficaciones profeslonales, Picote-Humanitas, Buenos Aires.

Naville, Pierre (1956). Essal sur la quallficatlon, Paris.

Rama, Germán y Sllveira, Sara (1991). Politt: cas de recursos humanos de la In- dustrla exportadora de Uruguay. Modernización $y$ desequillbrios. CEPAL-CINTERFORIOIT, Montevideo.

Thompson, Paul (1989). "Jugando a ser trabajadores cualificados: Cultura de fábrica y enorgullecimiento por la cualificación laboral entre los obreros del automóvil de Coventry", Soclología del Trabajo No. 7, España.

Thuderoz, Christian (1995). "Du fien social dans l'entreprise. Travail et individualisme cooperatif", Revue Françalse de Soclologle, XXXVI, Avril-Juin 1995.

Schultz, Theodore W. (1971). Investment In Human Capltal: The Role of Educatlon and Research. The Free Press, New York.

Zarifian, Phillppe (1993). "Los nuevos enfoques de la productividad", Ed. Unidad de Relaciones y Cooperación con el Sector Sindical-Universidad de la República, Montevideo.

(1994). "L'organisation quiallilante: de la qualité de l'apprentlssage professlonel a l'efflclence économlque", Mimeo.

Zarifian, Philippe y Veltz, Pierre (1994). "De la productivité des ressources a la productivité d'organisation", Mimoo. 